\title{
Implementation and Validation of a New Strategy of Online Practical Works of Power Electronics for Embedded Systems
}

\author{
https://doi.org/10.3991/ijoe.v13i04.6659 \\ Abdessamad Malaoui \\ Sultan Moulay Slimane University, Béni Mellal, Morocco \\ a.malaoui@uca.ac.ma \\ Monji Kherallah \\ University of Sfax, REGIM-Lab, Sfax, Tunisia \\ monji.kherallah@gmail.com \\ Lila Ghomri \\ Abdelhamid Ibn badis University, Mostaganem, Algeria \\ lilaghomri@yahoo.fr \\ Mustapha Raoufi \\ University of Cadi Ayyad, Marrakech, Morocco \\ a.raoufi@uca.ac.ma \\ Guillaume Andrieu \\ University of Limoges, France \\ guillaume. andrieu@xlim. fr \\ Thomas Fredon \\ University of Limoges, France \\ thomas.fredon@unilim.fr \\ Denis Barataud \\ University of Limoges, France \\ denis.barataud@unilim.fr
}

\begin{abstract}
This paper presents the implementation and validation of a Remote laboratory for Practical Works (PWs) of power electronics for embedded systems. This work falls within the framework of an international project between several universities of the Maghreb and Europe. The aim is to create a Remote Practical Laboratory of $3^{\text {rd }}$ year Bachelor degree in Electronics and Optics e-Learning for Embedded Systems (EOLES). This paper presents the topologies and architectures description of various realized practical manipulations and developed software/hardware platforms. The presented results relate to 3 PWs of the power electronics. The first two practical works (WP1 and WP2) are respectively, "Uncontrolled simple phase half and full wave rectifiers", While the PW3 deals the study of a Buck-converter connected on various loads.
\end{abstract}


Paper-Implementation and Validation of a new Strategy of Online Practical Works of Power Electronic...

The results are presented and discussed according to two levels. The first is a comparison of the results of electronic measurements with the theory. The second deals with comparison of this Remote system with the same PW performed by the classical method "in-class". Based on an analysis of the students Quality Assessment of these PWs, the results show the limits of validity and reveal the strengths and weaknesses of this new educational strategy in the University pedagogical system, and the possibility of its used in other types of training and disciplines.

Keywords-Remote Laboratory, Online Practical Works, e-Learning, Embedded Systems, Power Electronics, EOLES Project

\section{$1 \quad$ Introduction}

The courses and disciplines in the exact sciences are based on practical work which complements the theoretical teaching. In recent years, there have been anomalies in these formations in southern Mediterranean countries, particularly in open access institutions [1]. The high and growing number of students enrolled in these courses is the main factor in this imbalance, but there are also other factors such as the inadequacy of teaching skills in some disciplines and the high cost of practical teaching materials.

In recent years, researchers in this field have proposed several approaches and strategies to help find solutions to these challenges [2]. Most of these strategies are based on distance education and the use of Information Technologies (IT) and the remarkable development of embedded electronic systems [3]. The first problem in this type of education is the development of Practical Works, which really requires a serious thought to integrate this new educational approach and the adaptation of embedded systems in the remotely controlled laboratory.

In this work, we present an innovative experience mounted by an international project between several European and the Maghreb countries, to implement an educational laboratory of Remote Practical Work (PW) in the power electronics field for embedded systems [4]. This experience is validated by qualified international training bringing together dozens of students from these countries in a professional Bachelor (Electronics and Optics e-Learning for Embedded Systems) [5]. EOLES members skills were trained through this project to make and to install the hardware and software tools for Remote practical works, as well as coaching and teaching these PWs either synchronously or/and through developed and registered courses in a platform.

This paper deals, in particular with the overall architecture of the Remote Laboratory and the mounting of $3 \mathrm{PWs}$ in the field of power electronics. Results analysis of this practical teaching system are presented and discussed based on the two ways. The first is to compares the electrical measurements found by students with theatrical models. The second way tests of system reliability performed by students groups of $3^{\text {rd }}$ year and compare the PW results with classic educative system. 


\section{Framework and description of Remote Practical Works}

The EOLES project (Electronics and Optics e-Learning for Embedded Systems) is a European project (Tempus) who aims support the development of e-learning (distance learning) in Algeria, Morocco and Tunisia through the creation of a third year bachelor in electronics and optics, taught entirely in English. This $3^{\text {rd }}$ year of license is opened to all students regardless of their place of residence [6]. The first two years of the project were devoted to the development of equipment education (courses, practical work, etc.) and the development of Remote laboratory perspective as the concrete implementation of the Diploma in the last year of project.

The most innovative point of this project is the creation of a remote practical laboratory work fully online. This educative project is coordinated by the University of Limoges, it was have received a 1,28M€ funding from the European Union under the Tempus program. This project aims to create a diploma in third year in electronics and optics for embedded systems, taught in English. The most point's innovation of this project is the creation of a practical Remote laboratory. The diploma obtained by students is a joint diploma delivered by several consortium partners. EOLES was a 3 years project and it brings together 15 partner universities from seven Mediterranean countries (Algeria, Belgium, France, Morocco, Portugal, Romania and Tunisia). Validation and implementation of this project proves a best ability management to implement innovative proposals both in the scientific and pedagogical:

- Establishment of a training accessible entirely online including the realization of practical work online,

- Training modules also offered to teachers and staff involved,

- Use of social networks to enable exchange and mutual assistance between students.

\section{Architectures of Practical Works implementation}

The overall architecture of server connections requires equipping a laboratory in each Southern Mediterranean countries (Tunisia, Algeria, and Morocco). The three application serve relay the contact with the principal Remote lab in France (Limoges) with e-Learning Open Source platform "Moodle" to manage the communications and content (courses, practical works), according the architecture illustrated in the following figure 1. 


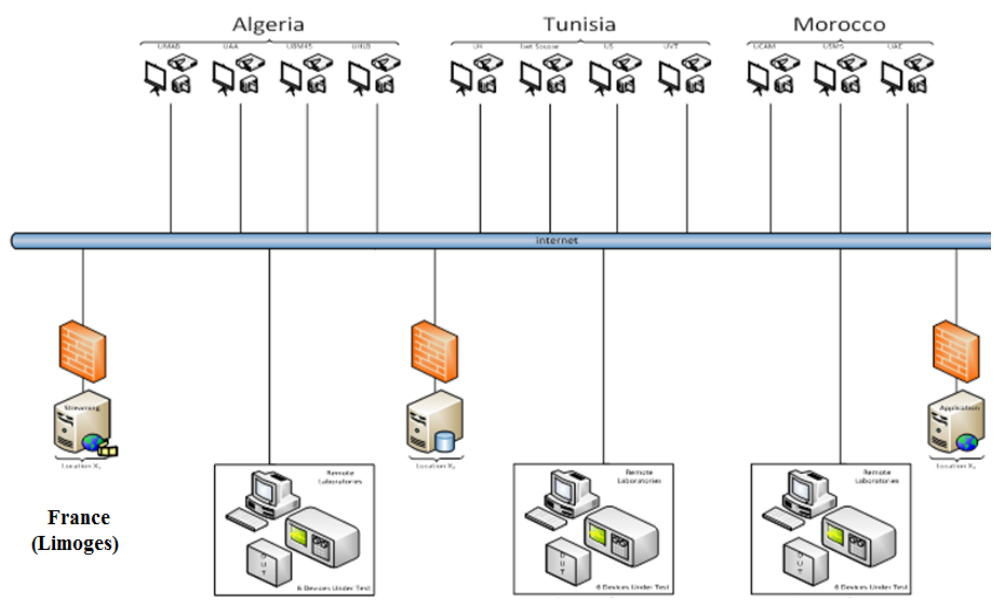

Fig. 1. Overall architecture of server connections

The architecture in the interior of each laboratory has a main server connected to a relay matrix system that controls manipulations using an embedded system "Arduino" or "PCduino" and measuring power devices (oscilloscope, GBF ...). The web interface design uses HTML (CSS) and JavaScript [7, 8]. The PW is graphically represented in web pages. Figure 2 illustrates the hardware architecture of the connection and the practical works.

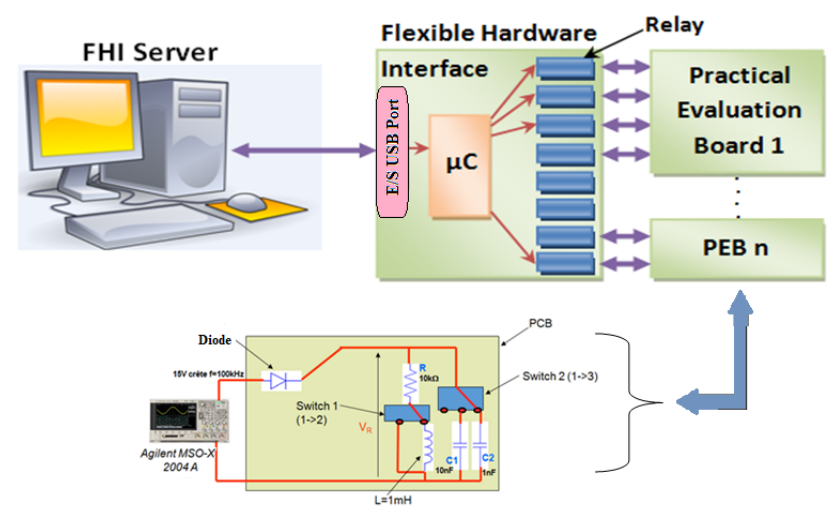

Fig. 2. Example of a Remote Practical Evaluation Board (PEB) architecture

\section{Used equipments in Remote Practical Laboratory}

To ensure the feasibility and functioning of practical works, we have reserved funding for the necessary equipments, servers, platforms and appropriate software. The assembly is connected in such a way as to form a single reconfigurable PW. This combination makes it easy to change the desired manipulation. 


\subsection{Measuring devices and Evaluation Board}

The implemented laboratory architecture is centered on a main server and uses many other types of equipment to be correctly connected [9]. This server is connected to several measuring devices and instruments such as:

- Switches remotely controlled by the student "1 toward 3",

- Printed circuit board containing the different components and relays controlled with an Ethernet Hardware Interface (EFHI) using embedded systems as Arduino.

- Waveform generator 33220A.

- 4 channel Digital oscilloscope DSOX3014 or MSOX2004A. The generator embedded in this oscilloscope drives the circuit and $V_{R}$ is measured with the part of the scope for each circuit configuration.

Those devices can be monitored from the different application server. This architecture has several advantages as the flexibility to control a large number of instruments and Remote Practical Evaluation Board (PEB) locally developed [10]. Also it is transparent to the user, which exactly the case when several instruments are used locally. Indeed the user will not need to know the nature of interface used on each instrument remotely controlled. On the other hand, the possibility to remotely control instruments, relays and others manipulations.

In Figure 3, we present the electronic circuit of a practical evaluation board in our PW. The passive elements of this circuit are controlled by relays and the matrix of different values (resistances, capacities and inductances) allows wiring of the desired electronic circuit diagram.
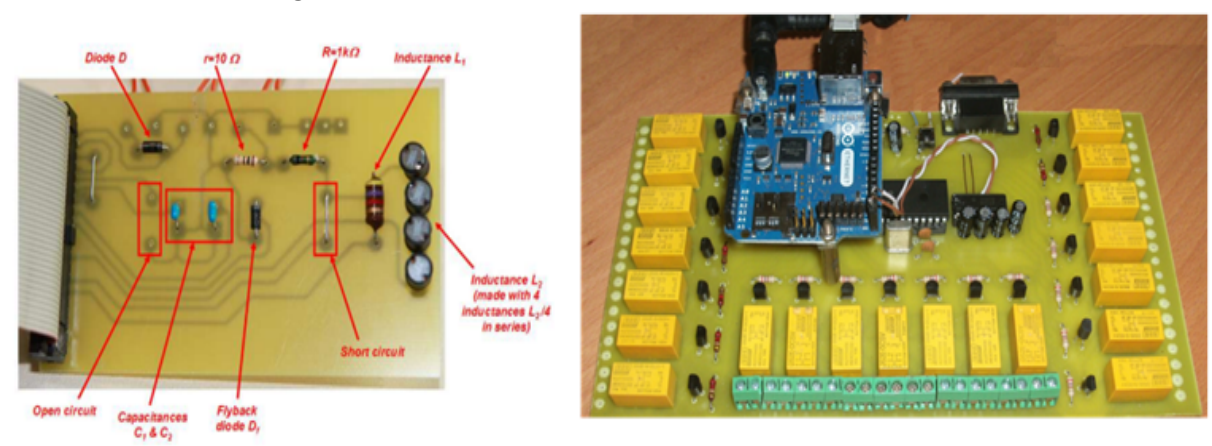

Fig. 3. Electronic schematic and realized Practical Evaluation Board (PEB)

\subsection{Software interface and learning equipments of PW}

The Learning Environment (LE) and developed Remote laboratory use the online classrooms at each institute of the partner countries, connected to the internet. It contains the following components:

- Camera, Microphone, writing board, speaker ....

- One server for Big Blue Button or Adobe-connect to record and keep the content (text, audio, video ...) of the lectures and (tutoring materials for) the practical works. 
This server helps to connect students, lecturers and tutors to Moodle learning platform.

- Remote lab servers installed in each Remote lab (Morocco, Tunisia and Algeria).

- Measuring equipment, DUT's, connections between equipment, measurement probes, software...

- Several PC's (and Arduino) "serving” the Laboratory set-ups.

\subsection{Practical Works steps}

Different steps are necessary to realize a practical work:

- Thinking (by Teacher) about the electronic circuit, its scheme and all different possible configurations allowed for the students,

- Conceiving the circuit, soldering the components, assembling the case,

- Programming the web page and all the possible configurations,

- Technical staff in each University plugging all the instruments to the case.

For a student, a practical work is composed of several links:

- One to each instrument's interface.

- One to the practical work's schematic.

- One to the IP-webcam.

- One to the practical work's text, written by the teachers.

The image of Fig. 4 shows the assembly of the remotely controlled mounting.

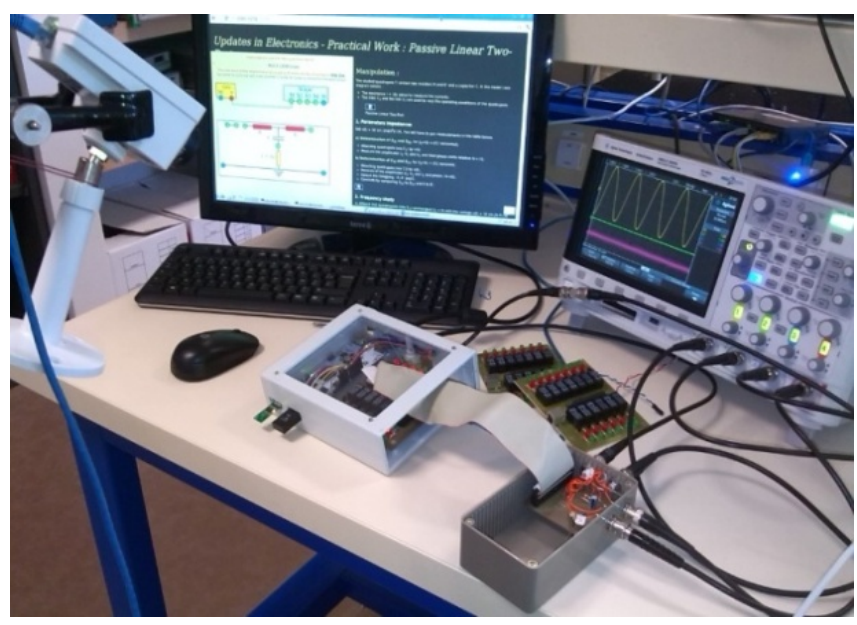

Fig. 4. Practical Works equipments

\section{Developed Practical Works}

In power electronics technical unit we have prepared two basic actions, namely rectifiers and back converter. The proposed PWs in this study are 3; their electronic diagrams are presented in Figure 5, 6 and 7. 
PW1: Uncontrolled single-phase half wave rectifier.

In figure 5, we present the electronic schema that corresponds to the first practical work (PW1).

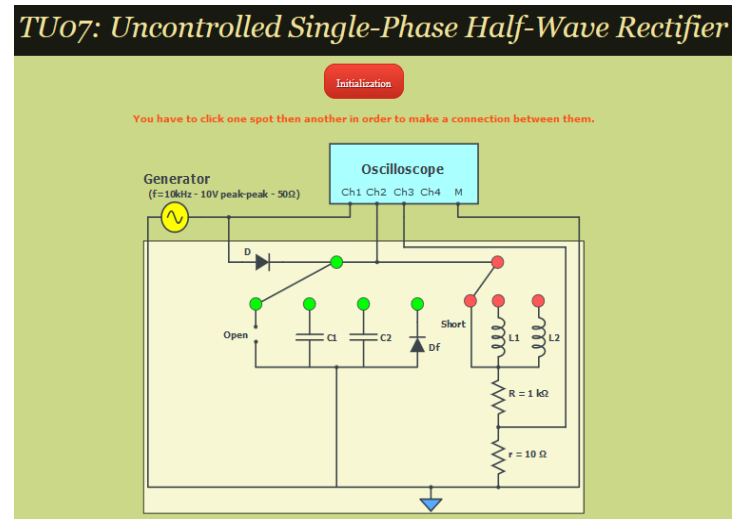

Fig. 5. Schema and interface of PW1

The objective of this PW is to manipulate an uncontrolled single-phase rectifier connected to different loads ( $\mathrm{R}, \mathrm{C}$ and $\mathrm{L}$ ). The tasks asked of the students are presented and explained later.

\section{PW2: Uncontrolled single-phase full wave rectifier.}

The objective of this second practical works (WP2) is to study the full-wave rectifier with different loads. Figure 6 shows the electronic schema and the online platform of this PW. In the same way, the tasks asked of the students are presented and explained later.

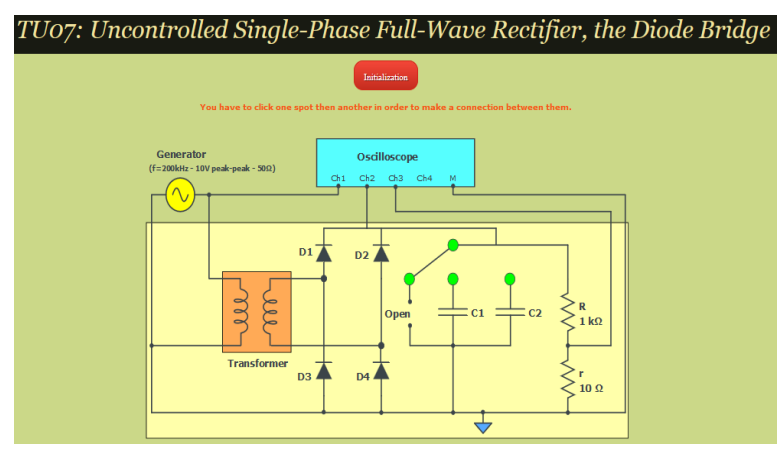

Fig. 6. Schema and interface of PW2

\section{PW3: Study of a Buck-converter connected on various loads.}

The connection of this PW3 with the equipment remotely connected is presented in the figure 7 . The screen of the oscilloscope and generator of functions are also remotely controlled. 


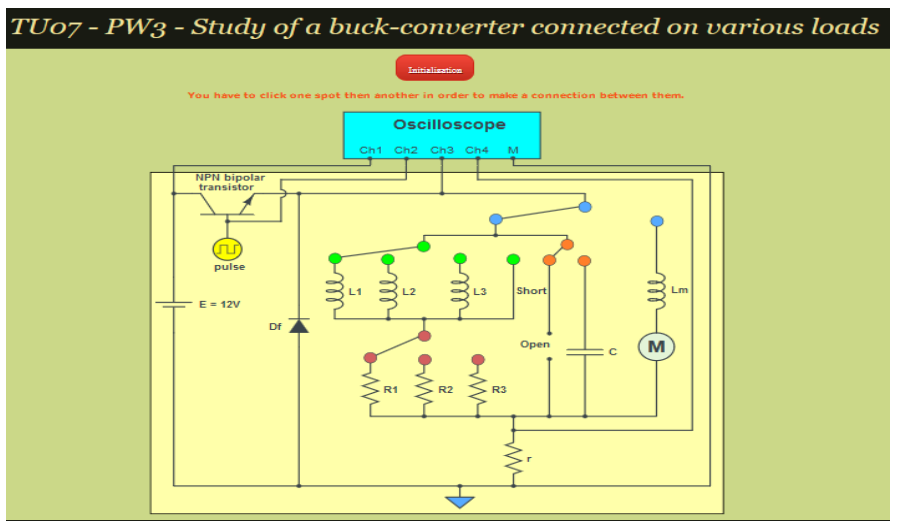

Fig. 7. Web page interface of PW3

Before beginning the manipulations, one must configure the waveform generator under the following values:

- Waveform: sinusoidal and frequency about $10 \mathrm{kHz}$.

- Magnitude: $10 \mathrm{~V}$ peak-peak.

For two Practical Works (PW1 and PW2) the required tasks of the students are the measurement of current and voltage characteristics to determine:

- Measurement of $\left\langle\mathrm{V}_{\mathrm{s}}\right\rangle=\mathrm{f}(\alpha)$ with a mean current $\mathrm{I}_{\mathrm{e}}$.

- Measurement of $\left.\left\langle\mathrm{V}_{\mathrm{s}}\right\rangle=\mathrm{f}\left(<\mathrm{I}_{\mathrm{s}}\right\rangle\right)$ with a constant duty cycle.

- Measurement of Vs and for the discontinuity condition of the current.

- Plot of $\mathrm{I}_{\mathrm{s}}=\mathrm{f}(\mathrm{t})$ graph.

The $V_{s}, I_{s}$, and $\alpha$ are respectively output voltage, output current in load and duty ratio. The student must explain how is it possible to know the current $i_{R}(t)$ through the load with the resistance " $r$ ". To achieve these tasks, the student must perform tree manipulations:

\section{Manipulation 1: with resistive load $(Z=R)$.}

The student is asked to perform the following tasks:

- Connect the load $\mathrm{R}$ at the output of diode (green switch on open, red switch on short).

- Measure $\left\langle\mathrm{V}_{\mathrm{R}}>, \mathrm{V}_{\mathrm{RMS}}\right.$, the form factor $\mathrm{F}$ and the ripple rate $\tau$. Is it possible to measure the threshold voltage of the diode (voltage between the anode and the cathode of a diode when the diode is "ON")?

- Justify and give your results.

The theoretical expressions of the measured parameters during PWs are given by:

- The mean value of the output voltage of $V_{R}$ is:

$$
<V_{R}>=\frac{1}{T} \int V(t) d t
$$

The Root-Mean-Square (RMS) of output voltage is: 


$$
V_{R M S}=\sqrt{\frac{1}{T} \int_{0}^{T}[V(t)]^{2}}
$$

The factor $\mathrm{F}$ and the ripple rate $\tau$ are given by:

$$
\begin{gathered}
F=\frac{V_{R M S}}{\left\langle V_{R}>\right.} \\
\tau=\frac{V_{\max }-V_{\min }}{\left\langle V_{R}\right\rangle}
\end{gathered}
$$

Manipulation 2: with $R$ in parallel with a capacitance $C(Z=R / / C)$.

Similarly, the student must perform:

- Connect successively capacitances $\mathrm{C}_{1}$ and $\mathrm{C}_{2}$ in parallel with the load R.

- After observing the rectified voltage $V_{R}$ obtained for each capacitance, what is the best capacitance between $\mathrm{C}_{1}$ and $\mathrm{C}_{2}$ ? Justify.

- Then, measure $\left\langle V_{R}\right\rangle, V_{R M S}$, the factor form $F$ and the ripple rate $\tau$ for the optimal capacitance. Compare with the results obtained with the load R. For this optimal capacitance, what is the ratio between the times when the diode is ON in comparison to the period $T$ of the signal? Thus, indicate if the current through the load $i_{R}(t)$ and the rectified voltage $V_{R}(t)$ are in phase.

The output capacity $\mathrm{C}$ is given by:

$$
C=\frac{t_{1}}{R \cdot \ln \left(\frac{V_{\max }}{V_{\min }}\right)}
$$

Where $t_{1}$ is time when $V\left(t_{1}\right)=V_{\text {min }}$.

$>$ Manipulation 3: Load $R$ in serie with an inductance, the RL load being in parallel with a diode

Students must follow the following steps:

- Connect successively inductances L1 and L2 in serie with the load R.

- Connect also the flyback diode Df in parallel to the RL load.

- Say what is the role of this diode Df? Is it playing correctly its role? Justify.

\section{$6 \quad$ Results and discussions}

The results of this work were carried out by two steps. The first step is a comparison of the electrical results, found directly with the instruments (oscilloscope, ammeter voltmeters ...), with those found by the theory. The second step is to compare with the same practical manipulations that are carried out in the classical 'face-to-face' system under the same conditions. The results of this last step are obtained by analyzing the answers of the questionnaires carried out by groups of 13 students in both systems (classical and Remote) PWs. 


\subsection{Results of electronic measurements}

In three practical works, students determine electrical quantities with different methods using the Remote oscilloscope measurements and theories. Several results have been obtained according to the 3 manipulations indicated in paragraph 5 , but it will be limited to giving just some results of these measures. Indeed, we will present 3 significant cases of these results:

\section{Results 1: Single-phase half wave rectifier on various resistive load.}

The voltage value of the threshold voltage of the diode (voltage between the anode and the cathode of a diode when the diode is "ON") is measured using two methods. The first method use the Math menu of the oscilloscope and second method compares $\mathrm{V}(\mathrm{t})$ and $\mathrm{V}_{\mathrm{R}}(\mathrm{t})$ voltage based on the current measurements as shown in figure 8. These results are compared with theory and presented in Table 1. It show the difference justified by measurement. We also compare the theory with other measured electrical quantities $\left(<\mathrm{V}_{\mathrm{R}}>, \mathrm{V}_{\mathrm{RMS}}, \mathrm{F}, \mathrm{V}_{\max }, \mathrm{V}_{\min }\right.$ and $\left.\tau\right)$. The values of this comparison are presented in Table 2.

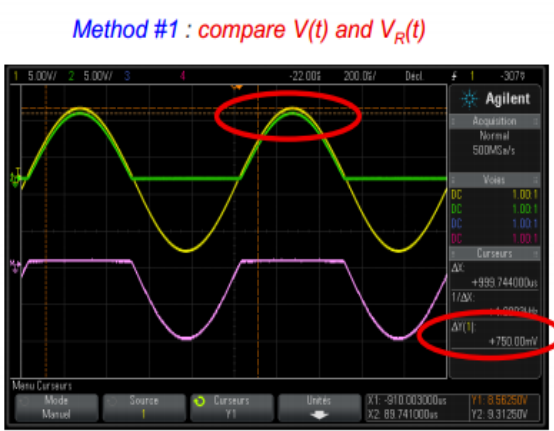

$V_{\gamma} \approx 0.75 \mathrm{~V}$
Method \#2: use the Math menu of the oscilloscope

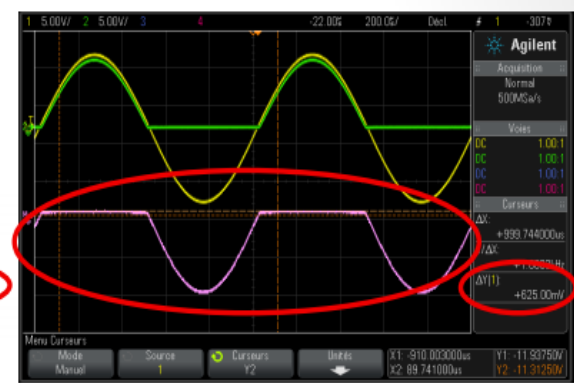

$V_{\gamma}=V(t)-V_{R}(t)=V_{C H 1}-V_{C H 2} \approx 0.625 V$

Fig. 8. PW measurements in Manipulation 1

Table 1. Comparison of the threshold voltage of the diode

\begin{tabular}{|l|c|c|c|}
\hline & Method 1 & Method 2 & Theory \\
\hline $\mathrm{V}_{v}$ (volts) & 0,75 & 0.625 & 0,7 \\
\hline
\end{tabular}

Table 2. Comparison of parameters measurement

\begin{tabular}{|c|c|c|}
\hline & Measurements & In theory (ideal diode) \\
\hline$<\mathrm{V}_{\mathrm{R}}>$ & $2.73 \mathrm{~V}$ & $3.18 \mathrm{~V}$ \\
\hline $\mathrm{VR}_{\mathrm{RMS}}$ & $4.38 \mathrm{~V}$ & $5 \mathrm{~V}$ \\
\hline $\mathrm{V}_{\max }$ & $9 \mathrm{~V}$ & $10 \mathrm{~V}$ \\
\hline $\mathrm{V}_{\min }$ & $0 \mathrm{~V}$ & $0 \mathrm{~V}$ \\
\hline $\mathrm{F}$ & 1.6 & 1.57 \\
\hline$\tau$ & 3.3 & 3.14 \\
\hline
\end{tabular}


These results show logical differences between measurements and theory. The differences of these values remain in the same level in the conventional PW.

\section{Results 2: Single-phase half wave rectifier on various loads $(Z=R / / C)$}

The student must seek by measure, the optimal capacitance $C$ at the output of the assembly (PW2) which gives good filtering. The measurements of the parameters $<\mathrm{V}_{\mathrm{R}}>, \mathrm{V}_{\mathrm{RMS}}, \mathrm{F}$ and $\tau$ for the best capacitance of $\mathrm{C}$ have given in Fig. 9 and Table 3:

Table 3. Comparison between measurements and theory

\begin{tabular}{|c|c|c|}
\hline & Measurements & In theory (ideal diode) \\
\hline$<\mathrm{V}_{\mathrm{R}}>$ & $6.65 \mathrm{~V}$ & $6.88 \mathrm{~V}$ \\
\hline $\mathrm{V}_{\mathrm{RRMS}}$ & $6.68 \mathrm{~V}$ & $6.90 \mathrm{~V}$ \\
\hline $\mathrm{V}_{\max }$ & $8 \mathrm{~V}$ & $8.98 \mathrm{~V}$ \\
\hline $\mathrm{V}_{\min }$ & $5.3 \mathrm{~V}$ & $5.45 \mathrm{~V}$ \\
\hline $\mathrm{F}$ & 1.004 & 1 \\
\hline$\tau$ & 0.4 & 0.34 \\
\hline
\end{tabular}
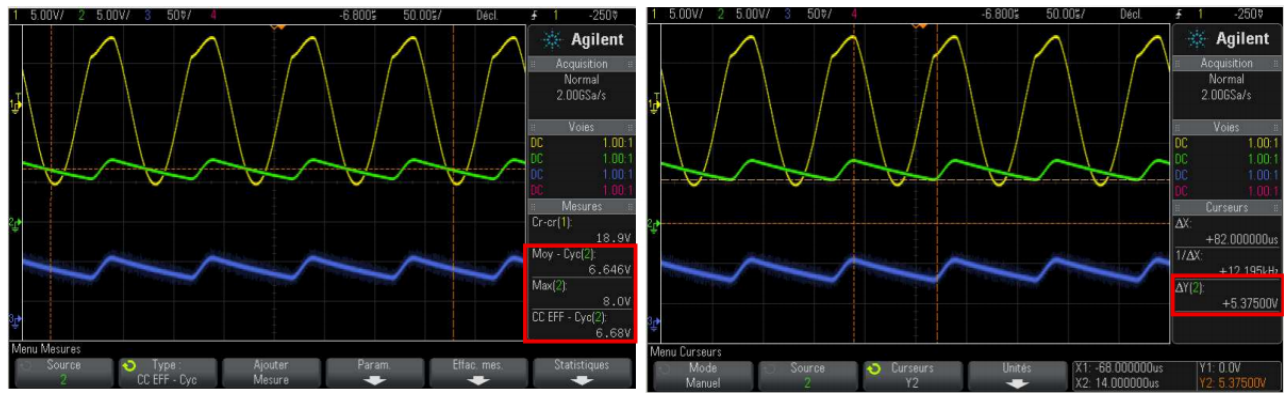

Fig. 9. PW measurements in Manipulation 2

For this optimal capacitance, students can determine the ratio between the time ( $\mathrm{T}$ "ON") when the diode is "ON" in comparison to the period " $\mathrm{T}$ " of the signal. They can also verify if the current through the load $i_{R}(t)$ and the rectified voltage $V_{R}(t)$ are in phase. The values and equations of these tasks are:

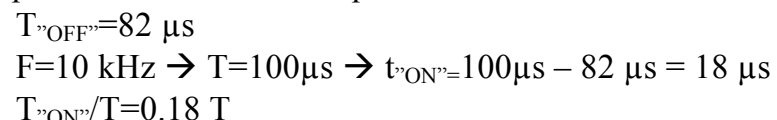

$\mathrm{T},{ }_{\mathrm{ON}}, / \mathrm{T}=0.18 \mathrm{~T}$ 
Determine experimentally the value of $\mathrm{C} 2$ thanks to the knowledge of the differential equation of a RC circuit.

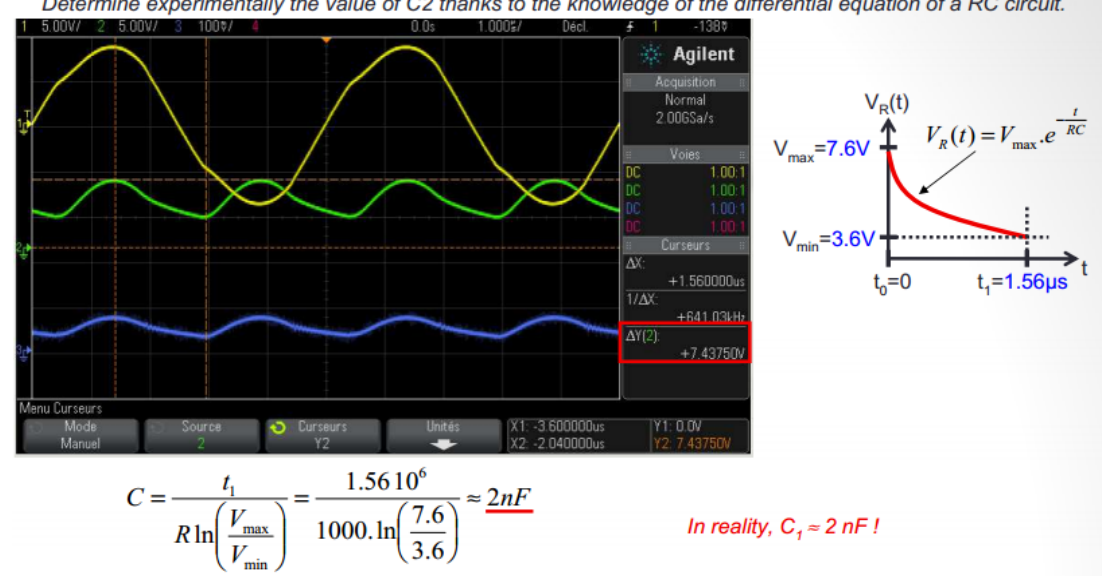

Fig. 10. Determination of optimal capacitance in Manipulation 2

\section{Results 3 : Load $R$ in serie with inductance $L$, the $R_{L}$ load being in parallel with a diode}

In this manipulation, students can measure if the current through the load $i_{R}(t)$ and the rectified voltage $V_{R}(t)$ are in phase. They can also verify the origin of the problem concerning the rectified voltage $\mathrm{V}_{\mathrm{R}}(\mathrm{t})$. They show the effect of the optimal value of the inductance (L1 and L2) on the signal stability at the output. The current $\mathrm{I}_{R}(\mathrm{t})$ and voltage $V_{R}(t)$ are no longer in phase. The problem concerns the fact that $V_{R}(t)$ is sometimes $<0$. The $\mathrm{V}_{\mathrm{R}}(\mathrm{t})$ value is not a rectified voltage, but the flyback diode plays correctly its role; the $V_{R}(t)$ is now never $<0$ as presented in fig. 11 .

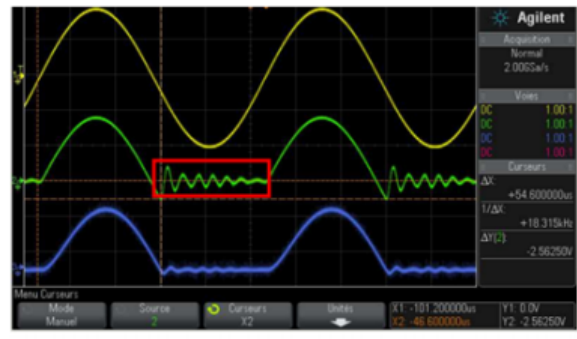

Inductance $L_{1}$

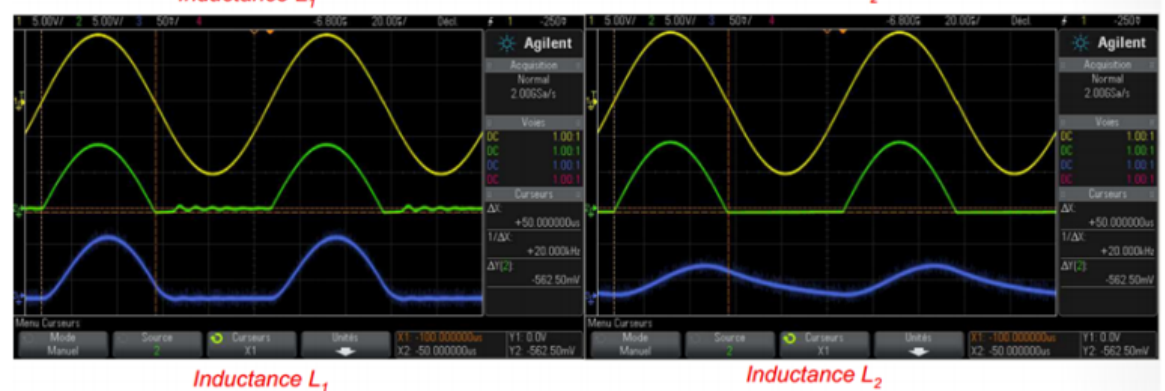

Fig. 11. Role of Df diode in Manipulation 3

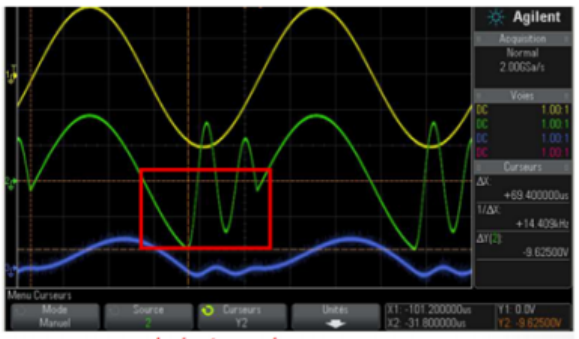

Inductance $L_{2}$ 
It is clear that the found measurements in the $3 \mathrm{PWs}$ are makes with relative errors comparable to those found in general in the conventional PWs. These errors show the degree of student understanding who perform these manipulations. To better argue these degrees, another comparative section of the results was carried out by comparing the two educational systems of practical works.

\subsection{Comparison with the classical system}

This second part concerns the analysis of the responses of a given questionnaire to two groups of students of 13 persons in each. The first group is made up of students from the EOLES training, while the second group consists of students from the 3rd year of the "electronic" course of the SMP classical training in Sultan Moulay Slimane University (Béni Mellal - Morocco). These two groups realized the same practical works (PW1, PW2 and PW3). The questions posed to these two groups are divided into two categories; the open questions (Q1, Q2, Q3 and Q4) and closed questions (Q5 and Q6) see Tables 4 and 5. A Kj Factor which is calculated according to equations (6) and (7).

$$
\begin{gathered}
S=\frac{1}{N} \cdot \sum_{j} R_{j} \\
K=\frac{S}{M} \cdot 100 \%
\end{gathered}
$$

The "S" and "K" represent respectively the average student response for each question, and the percentage of that average in relation to the high value. The "Rj" term is the answer of the student $\mathrm{j}$ for each question.

\begin{tabular}{|c|c|c|c|c|}
\hline Factor & Questions & Level of response & $\begin{array}{c}\text { Remote PW } \\
(\%)\end{array}$ & $\begin{array}{l}\text { Classical } \\
\text { PW (\%) }\end{array}$ \\
\hline $\mathrm{K}_{1}$ & $\begin{array}{l}\text { Q1: How difficult is it to have } \\
\text { access to all the different PW } \\
\text { elements? }\end{array}$ & $\begin{array}{l}4-\text { No problem } \\
3 \text { - Few minor difficulties } \\
2 \text { - Quite difficult } \\
1 \text { - Very difficult } \\
\end{array}$ & 86.5 & 92.25 \\
\hline $\mathrm{K}_{2}$ & $\begin{array}{l}\text { Q2: Are the PW documents clear } \\
\text { enough about what you have to } \\
\text { do? }\end{array}$ & \begin{tabular}{|l|}
$4-$ Very clear \\
3 - Quite clear \\
2 - Not very clear \\
1 - Not clear at all \\
\end{tabular} & 84.5 & 90.75 \\
\hline $\mathrm{K}_{3}$ & $\begin{array}{l}\text { Q3: How difficult is it to handle } \\
\text { all the practical work's elements? }\end{array}$ & $\begin{array}{l}4-\text { No problem } \\
3 \text { - Few minor difficulties } \\
2 \text { - Quite difficult } \\
1 \text { - Very difficult }\end{array}$ & 78.75 & 86.5 \\
\hline $\mathrm{K}_{4}$ & $\begin{array}{l}\text { Q4: According to you, does this } \\
\text { practical work match the theoret- } \\
\text { ical concepts? }\end{array}$ & $\begin{array}{l}4 \text { - Yes, totally } \\
3 \text { - Yes, partially } \\
2 \text { - Not so much } \\
1 \text { - Not at all }\end{array}$ & 88.5 & 91.25 \\
\hline
\end{tabular}

Table 4. Results of closed questions

The "N" represents the number of students in each group and the "M" is the number of answers given for each question (in our $\mathrm{N}=13$ and $\mathrm{M}=4$ ). The results of the 
closed questionnaire are given in Table 4. The results of the closed questionnaire are given in Table 5:

Table 5. Results of open questions

\begin{tabular}{|l|c|c|}
\hline \multicolumn{1}{|c|}{ Questions } & $\begin{array}{c}\text { Time (mn) } \\
\text { Remote PW }\end{array}$ & $\begin{array}{c}\text { Time (mn) } \\
\text { Classical PW }\end{array}$ \\
\hline $\begin{array}{l}\text { Q5: How long did you take for this practical work's (handling } \\
\text { the webpage, handling the instruments, doing the measure- } \\
\text { ments, etc)? Your answer should be in minutes. }\end{array}$ & $\begin{array}{c}105 \\
(1 \mathrm{~h} 45)\end{array}$ & $\begin{array}{c}122 \\
(\approx 2 \mathrm{~h})\end{array}$ \\
\hline $\begin{array}{l}\text { Q6: How long did you take to process the results and write } \\
\text { this practical work's report? Your answer should be in min. }\end{array}$ & $\begin{array}{c}133 \\
(\approx 2 \mathrm{~h} 15)\end{array}$ & $\begin{array}{c}186 \\
(3 \mathrm{~h} 06)\end{array}$ \\
\hline
\end{tabular}

The analysis of the Table 4 results shows several important points. The satisfaction of the students who exercise the two types of PWs never reach $100 \%$ but is greater than $75 \%$ according to the measure of the " $\mathrm{K}_{j}$ " factor. Also the classical PW remain the most preferred among the students of this training; May be a psychological effect of students who prefer to touch the components and calibrate the electronic measuring instruments with their hands. On the other hand, it is noted that the measured values of the " $\mathrm{K}_{\mathrm{j}}$ " factors relative to the Remote PW approaches to those of the classical PW with a variation between $2.75 \%$ and $7.75 \%$. In Table 5, it is clear that Remote PW makes it possible to optimize the time of the practical manipulations and the overall time to write its reports. This time saving varies between $20 \%$ and $50 \%$ of the overall time, which allows taking advantage to program a series of PWs for 24 hours.

\section{Conclusion}

In this paper we have presented a detailed description of a Remote Laboratory for Practical Works of power electronics for embedded systems. This remote Lab is implemented in framework of an inter-university cooperation to create a Remote PWs of 3rd year Bachelor degree. The objective of this work is to present the various components of the developed remote laboratory, namely the chosen architectures, used software platforms, developed hardware and PWs prototypes to test and validate the performance of this installation. The studied and developed PWs in this laboratory are the uncontrolled single-phase half wave and full wave rectifiers and a Buck-converter. The results show that realized PWs are very similar to those in classic face to face. This developed platform is exploitable and easily adapted to other PWs techniques such as choppers, inverters, etc. This promising first experience has proven that it is capable of competing with conventional practice education systems. Also, it can be a complementary alternative to current learning systems, and can solve several problems encountered in the classical education system. The developed architecture can be improved and adapted to other disciplines and areas of technical education. Several other sides remain to be studied by scientific research in order to know the impact of these laboratories, namely the economic side, social, health, psychology, educative and others. 


\section{Acknowledgment}

The EOLES project referenced by "530466-TEMPUS-1-2012-1-FRTEMPUSJPCR" is funded by the European Commission. Authors of this work, thank all the staffs are working on this project which have contributed to its success.

\section{$9 \quad$ References}

[1] F. Schauer, F. Lustig, J. Dvorak and M. Ozvoldova, "Easy to build Remote laboratory with data transfer using ISES-Internet School Experimental System", European Journal of Physics, 29, 1-13, (2008). https://doi.org/10.1088/0143-0807/29/4/010

[2] Abdessamad MALAOUI, Monji KHERALLAH, Lila GHOMRI, Guillaume ANDRIEU, Denis BARATAU. "New strategy for remote Practical Works in Power Electronics for Embedded Systems: Application in EOLES European Project". Third International AfroEuropean Conference for Industrial Advancement AECIA'2016, Nov 21-23, (2016).

[3] Malaoui Abdessamad. "Low cost pedagogic device for Practical Works using embedded system". 2015 IEEE/ACS 12th International Conference of Computer Systems and Applications (AICCSA), pp. 1-8, Marrakech, (2015)

[4] Gericota, M. ; Barataud, D. ; Andrieu, G. ; De Craemer, R. ; Cristea, M.; Benachenhou, A. ; Ankrim, M. ; Bouchlaghem, K. ; Ferreira, P. "The EOLES project Remote labs across the Mediterranean", 11th International Conference on Remote Engineering and Virtual Instrumentation (REV) . pp.211-216, (2014).

[5] EOLES Project, (http://www.eoles.eu)

[6] Guillaume Andrieu, Said Farah, Fredon Thomas, André Vaz Fidalgo, Abdelhalim Benachenhou, et al.. Overview of the first year of the L3-EOLES training. REV2016: 13th International Conference on Remote Engineering and Virtual Instrumentation, 2016, Feb 2016, Madrid, Spain. pp.211-216, (2016). https://doi.org/10.1109/REV.2016.7444511

[7] Abdelmoula ABOUHILAL, Mohamed MEJDAL, Abdessamad MALAOUI. "Design and development of Practical Works for Remote Laboratories". The International Arab Conference on Information Technology (ACIT), Béni Mellal, 6-8 December (2016).

[8] H. Saliah-Hassane, M. Saad, W. K. Ofosu, K. djibo, H. A. Mayaki and M. M. Dodo Amadou, “LAB@HOME: Remote laboratory evolution in the cloud computing era”, American Society for Engineering Education, AC 2011-2530, (2011).

[9] J. García-Zubia, P. Orduna , I. Angulo, J. Irurzun and U. Hernández, "Towards a Distributed Architecture for Remote Laboratories", International Journal of Online Engineering iJOE, Vol. 4, : REV2008, July (2008).

[10] Said Farah, Abdelhalim Abdelhalim, Guillaume Neveux, Denis Barataud, Guillaume Andrieu, Thomas Fredon. "Multi-User and Real-Time Flexible Remote Laboratory Architecture for Collaborative and Cooperative Pedagogical Scenarios" International Journal of Online Engineering iJOE 12(4), pp. 33-36 (2016).

\section{Authors}

Abdessamad MALAOUI is an Associate Professor with Sultan Moulay Slimane University, Béni Mellal, Morocco. (a.malaoui@usms.ma) 
Monji KHERALLAH is an Associate Professor with University of Sfax, REGIMLab, Sfax, Tunisia. (monji.kherallah@gmail.com)

Lila GHOMRI is an Associate Professor with Abdelhamid Ibn badis University, Mostaganem, Algeria. (lilaghomri@yahoo.fr)

Mustapha RAOUFI is an Associate Professor with University of Cadi Ayyad, Marrakech, Morocco. (a.raoufi@uca.ac.ma)

Guillaume ANDRIEU is an Associate Professor with University of Limoges, France. (guillaume.andrieu@xlim.fr)

Thomas FREDON is a Engineer in University of Limoges, France. (thomas.fredon@unilim.fr)

Denis BARATAUD is an Associate Professor with University of Limoges, France. (denis.barataud@unilim.fr)

Article submitted 16 January 2017. Published as resubmitted by the authors 13 March 2017. 